\title{
Mutational analysis of SMN gene in patients with spinal muscular atrophy and the correlation between mutation and the severity of clinical manifestations
}

\begin{abstract}
Almagul Nagimtaeeva ${ }^{1}$, Dina Zhanatae
${ }^{1}$ National research center for maternal and child health ${ }^{1}$ National research center for maternal and child health
of the Corporate Fund "UMC", Astana, Kazakhstan
\end{abstract}

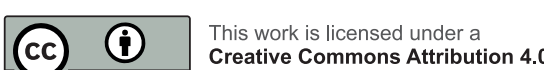
International License

\section{УДК 616.81-007.2:611.018.05}

J CLIN MED KAZ 2017; 3(45 SUPPL 3):18-21 Автор для корреспонденции: Марат Айзада, Акушерское отделение №2, “University Medical Center” Национальный научный центр материнства и детства. Адрес: Казахстан, Астана, пр. Туран, 32. Тел.: +77057837472

E-mail: Aizadamarat0708@gmail.com;

\section{$a^{1}$, Bakytgul Kamalieva ${ }^{1}$, Gulshara Abildinova ${ }^{1}$}

\section{ABSTRACT}

Objective: studying of mutations in the SMN1, SMN2 and NAIP genes in the diagnosis of spinal muscular atrophy and determining the correlation between the mutation and the severity of clinical manifestations.

Methods: 82 children with suspicion of spinal muscular atrophy were examined. Genomic DNA was isolated from the whole blood of patients using the Wizard $®$ Genomic DNA Purification kit (Promega). Further diagnostics was carried out using the MLPA method on a 96-capillary automatic analyzer 3730xl DNA Analyzer. The results were processed using the software Coffalyser DB.v.130.

Results: A homozygous deletion of the exons 7-8 of the SMN1 gene was observed in all SMA patients of this study. At the same time, the deletion of the exon 7 of the SMN1 gene and an increase in the number of copies of SMN2, 1 (2\%) and $2(4 \%)$, respectively, were found among patients with type II and III type of SMA. In the analysis of deletions of exons 7-8 of the SMN1 gene, the SMN1 gene was completely deleted in $15(29 \%), 2(4 \%)$ and 1 (2\%) SMA I, II and III patients.

The study revealed that the NAIP gene was deleted in 8 patients (19.2\%) with type I CMA and in two patients (4\%) with SMA type II. Also, in a single patient with a type II SMA, deletions of the exon 8 of the SMN1 1 gene $(2 \%)$ was found.

Conclusion: the MLPA method allows not only to confirm the diagnosis of spinal amyotrophy, but also to specify the type of spinal amyotrophy depending on the detected changes in the SMN1, SMN2 and NAIP genes. The clinical diagnosis of SMA is mainly based on the identification of homozygous deletions of the 7th and 8th exons of the SMN1 gene. Deletion of the NAIP gene and an increase in the number of copies of SMN2 are considered to assess the clinical phenotype of CMA patients.

Keywords: spinal muscular atrophy, genes SMN1, SMN2 and NAIP, MLPA - method, deletion.

ТҰЖЫРЫМДАМА

СПИНАЛЬДЫ БҰЛШЫҚЕТ АТРОФИЯСЫМЕН АУЫРАТЫН НАУҚАСТАРДА SМN ГЕННІҢ МУТАЦИЯЛЫҚ ТАЛДАУЫ ЖӘНЕ МУТАЦИЯ МЕН КЛИНИКАЛЫҚ КӨРІНІСТЕРДІН АУЫРЛЫҒЫ АРАСЫНДАҒЫ БАЙЛАНЫС

Нагимтаева А.А. ${ }^{1}$, Жанатаева Д.Ж. ${ }^{1}$, Камалиева Б.О. ${ }^{1}$, Әбілдинова Г.Ж. ${ }^{1}$

1 «UMC» корпоративтік қорының Ана мен бала ұлттық ғылыми орталығы, Астана, Қазақстан

Зерттеу мақсаты: Спинальды бұлшықетті атрофиясының диагностикасында (CБA) SMN1, SMN2 және NAIP гендеріндегі мутацияларды зерттеу және мутация мен клиникалық көріністердің ауырлығы арасындағыбайланыстыанықтау.

Әдістері:Спинальдыбұлшықетті атрофия күдікпен 82 бала тексерілді. Genomic DNA Wizard® Genomic DNA Purification Kit (Promega) жиынтық көмегімен пациенттердің тұтас қанынан геномдық ДНҚ бөлектелген. Әрі қарай, 96 капиллярлық автоматты 3730xI DNA Analyser анализатор арқылы MLPA әдісімен диагностика өткізілді. Қорытындылар Coffalyser DB.v.130 бағдарламалық жасақтама арқылы өңделді.

Нәтижелері: Өткізілген зерттеуде барлық пациенттерде SMN1 геннің7-8 экзондарында гомозиготтық делеция анықталды. Бес пациентте СБА 1 типімен SMN1 геннің7 экзонда гомозиготтық делеция анықталды. Сонымен қатар, СБА II және III типтері бар науқастардың арасында SMN1 генінің 7 экзонының делециясы және SMN2 ген генінің көшірмелерінің көбеюі анықталды, $1(2 \%)$ және 2 (4\%), тиісінше. SMN1 генінің 7-8 экзондарын делециясын талдау кезінде, I, II және III типтермен СБА науқастарда 15 (29\%), 2 (4\%) және 1 (2\%) SMN1 генде толықтай делеция көрсетілген. 
Зерттеу қорытындысы бойынша, СБА I типімен 8 науқаста (19,2\%) және СБА II типімен 2 науқаста (4\%), NAIP генде делеция анықталды және СБА II типімен 1 науқаста 1(2\%) SMN1 генінің 8 экзонның делециясы байқалды.

Қорытынды: MLPA әдісі спинальды бұлшықетті атрофиясының тек қана диагностикалауды ғана емес, SMN1, SMN2 және NAIP гендерінде анықталған өзгерістерге байланысты спинальды бұлшықетті атрофиясының түрін анықтауға мүмкіндік береді. СБА клиникалық диагнозы ең бастысы SMN1 генінің 7-ші және 8-ші экзондарының гомозиготтық делециясын сәйкестендіруде негізделген. СБА науқастарының клиникалық френотипін бағалау үшін NAIP генінің делециясы және SMN2 көшірмелерінің көбеюі қарастырылады.

Маңызды сөздер: Спинальды бұлшықетті атрофия, гендер SMN1, SMN2 және NAIP, MLPA - әдісі, делеция.

\section{PEЗЮME}

МУТАЦИОННЫЙ АНАЛИЗ SМN ГЕНАУ ПАЦИЕНТОВ СО СПИНАЛЬНОЙ МЫШЕЧНОЙ АТРОФИЕЙ И СВЯЗЬ МЕЖДУ МУТАЦИЕЙ И ТЯЖЕСТЬЮ КЛИНИЧЕСКИХ ПРОЯВЛЕНИЙ.

Нагимтаева А.А ${ }^{1}$,Жанатаева Д.Ж. ${ }^{1}$, Камалиева Б.О. ${ }^{1}$, Абильдинова Г.Ж. ${ }^{1}$

${ }^{1}$ Национальный научный центр материнства и детства корпоративного фонда «UMC», г. Астана, Казахстан

Цель исследования: изучение мутаций в генах SMN1, SMN2 и NAIP в диагностике спинальной мышечной атрофии и определение связи между мутацией и тяжестью клинических проявлений.

Методы: Было обследовано 82 ребенка с подозрением на спинальную мышечную атрофию. Из цельной крови пациентов была выделена геномная ДНК с применением набора Wizard®GenomicDNAPurificationkit (Promega). В дальнейшем была проведена диагностика с использованием метода MLPA на 96-капиллярном автоматическом анализаторе 3730xIDNAAnalyser. Обработку результатов осуществляли с помощью программного обеспечения CoffalyserDB.v.130

Результаты: У всех пациентов CMA в проведенном исследовании, обнаружена гомозиготная делеция экзонов 7-8 гена SMN1. У пяти пациентов со CMA 1 типа выявлена гомозиготная делецию экзона 7 гена SMN. B тоже время, среди пациентов со II и III типом CMA выявлена делеция экзона 7 гена SMN1 и увеличение числа копий SMN2, 1 (2\%) и 2 (4\%), соответственно. При анализе делеций экзонов 7-8 гена SMN1 показано, что у 15 (29\%), 2 (4\%) и 1 (2\%) больных CMA I, II и III типа ген SMN1 полностью делетирован.

В результате исследования выявлено, что ген NAIP делетирован у 8 пациентов (19,2\%) со СMA I типа и у двоих пациентов (4\%) со CMA II типа. Также, у одного пациента со CMA II типа была обнаружена единственная копия экзона 8 гена SMN1 1(2\%).

Заключение: метод MLPA позволяет не только подтвердить диагноз спинальной амиотрофии, но и уточнить тип спинальной амиотрофии в зависимости от выявленных изменений в генах SMN1, SMN2 и NAIP. Клинический диагноз СMA главным образом основан на идентификации гомозиготной делеции 7-го и 8-го экзонов гена SMN1.

Делеции гена NAIP и увеличение числа копии SMN2 рассматривают для оценки клинического фенотипа пациентов СМА

Ключевые слова: спинальная мышечная атрофия, гены SMN1, SMN2 и NAIP, MLPA-метод, делеция

\section{Введение}

Спинальная мышечная атрофия (СМА) представляет собой аутосомно-рецессивное нервно-мышечное заболевание,

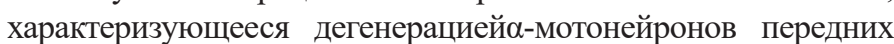
рогов спинного мозга. CMA впервые описана G. Werdnig в 1891 году в журнале «Архив психиатрии и неврологии», где представлены патоморфологические изменения различных групп мышц, спинного мозга и периферических нервов, а также было предположен наследственный характер заболевания.

По опубликованным научным данным, распространенность заболевания составляет 1 случай на 6-10 тысяч новорожденных[1, 2]. Большинство СМА наследуются по аутосомно-рецессивному типу. Ген SMN (survivalmotorneurongene) локализован в районе 5q13 и представлен двумя копиями гомологичных генов, образовавшихся вследствие появления копий одного генапредшественника.

Гены SMN1 (теломерная копия) и SMN2 (центромерная копия) отличаются по кодирующей последовательности только одним нуклеотидом [3] и нуклеотидная замена 840С > T в 7-м экзоне гена SMN2 приводит к снижению транскрипции и дефициту нормального стабильного белка SMN. Около 94\% пациентов с СМА обнаружено отсутствие обеих копий SMNэкзона 7, что имеет следствием к значимой потере белка[4]. Кроме того, крупные делеции или точечные мутации также могут быть причинами потери SMN1. Доказано, что SMN1 является основным поставщиком белка SMN, тогда как SMN2 может способствовать синтезу небольшого количества SMN белка. Количество копий SMN2 обратно пропорционально тяжести заболевания. Примерно у 90 \% пациентов с различными типами СМА выявленыделеции SMN1 в 7-8 экзонах. В дополнение к генам SMN, генNAIP, также расположенный в хромосоме 5q13.2, рассматривают как детерминирующий ген для спи ᄀнальной мышечной атрофии[5]. Отмечено, что число копии NAIP, коррелируется с тяжестьюСМА. У пациентов с СМА с меньшим количеством копий NAIP или их отсутствием диагностировали тяжелые формы заболевания, чем пациенты с большим количеством копий NAIP [6]. Кроме того, начало заболевания, клиническое течение и прогноз СМА были связаны не только с делецией в генах SMN, но и числами копии NAIP гена [7]. Обнаружение делеции 7 и/или 8 экзонов гена SMN1 в гомозиготном состоянии позволяет подтвердить диагноз СМА у больного, a повышение количества копий гена SMN2 способно компенсировать нехватку белка SMN, приводят к смягчению течения заболевания (формы II-IV), в то время как отсутствие гена NAIP указывает на крупнуюделецию в локусе SMN.

Поэтому, объяснение генных чисел копии и структур SMN1, SMN2 и NAIP важно для анализа молекулярного механизма и клинических особенностей СМА.

Цель: изучение мутаций в генах SMN1, SMN2 и NAIP в диагностике спинальной мышечной атрофии и определение связи между мутацией и тяжестью клинических проявлений.

\section{Материалы и методы}

Было обследовано 82 пациента с подозрением на спинальнуюатрофию. В группу исследованиявошли 52 пациента с диагнозом CMA I-III типов. Диагноз СМА устанавливался на основании наличия типичных клинических проявлений (прогрессирующий вялый паралич конечностей в сочетании с фасцикуляциями в зоне пораженных мышц) и электромиографических данных (наличие спонтанной переднероговой активности при проведении электромиографии (ЭМГ) с мышц верхних и нижних конечностей), свидетельствующих о поражении мотонейронов спинного мозга.

Из цельной крови пациентов была выделена геномная ДНК с применением набора Wizard®GenomicDNAPurificati onkit (Promega). В дальнейшем была проведена диагностика c использованием метода MLPAна 96-капиллярном 
автоматическом анализаторе 3500xIDNAAnalyser.Метод MLPA проводился согласно инструкциипроизводителя.

На рисунке 1 приведен пример электрофореграммыпациента с болезнью Кугельберга-Веландера, где отмечается делецияэкзонов 7-8 гена SMN1 и увеличение числа копий гена SMN2. Результаты интерпретировались по отсутствию пиков соответствующих экзонам7-8 гена SMN1 и увеличению пиков экзонов 7-8 гена SMN2 в 1,5 раза относительно реферсных значений.
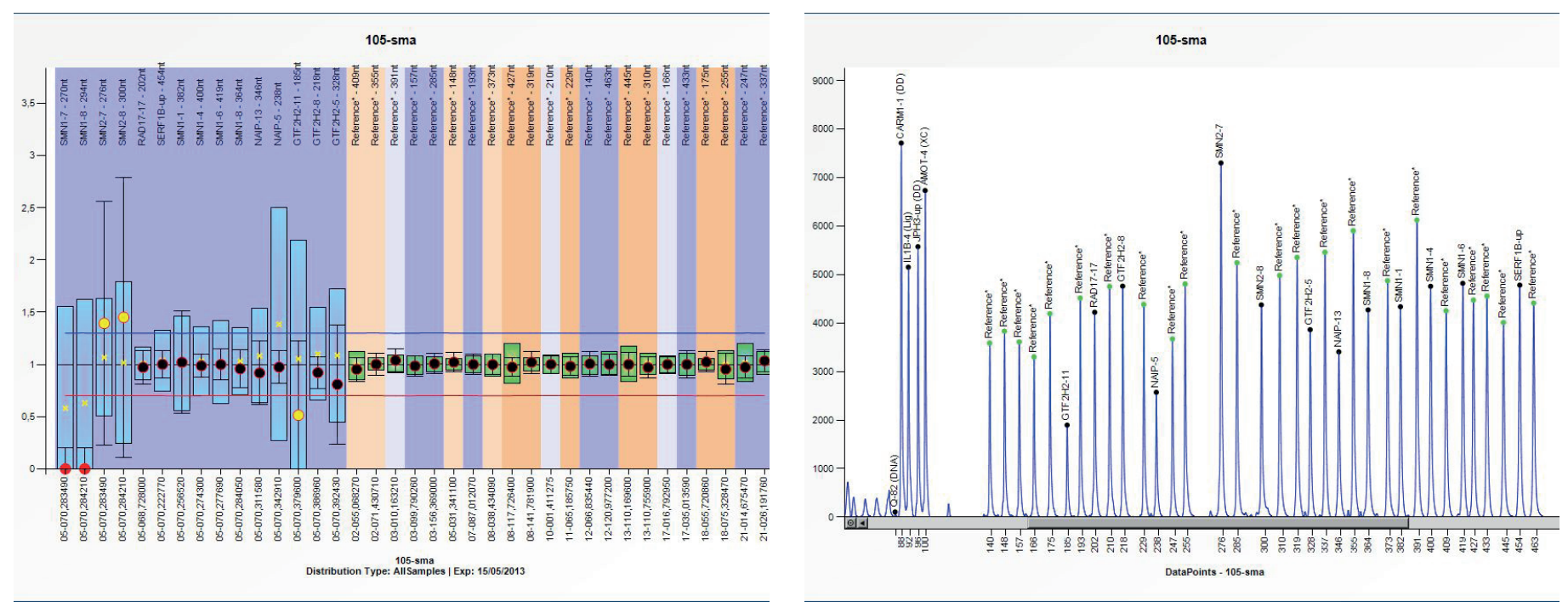

Рисунок 1- Результаты MLPA-анализа у пациента с III типом CMA.

\section{Результаты}

Методом MLPA-анализа подтверждены мутации в генах SMN1, SMN2 и NAIPу 52 из 82 обследованных пациентов.

Как видно из таблицы 1 у всех пациентов СМА в проведенном исследовании, обнаружена гомозиготная делецияэкзонов 7-8 гена SMN1. Мы также определили гомозиготную делецию экзона 7 гена SMN1 у 5 пациентов со CMA 1 типа (10\%). В то же время среди пациентов со II и III типом CMA выявлена делеция экзона 7 гена SMN1 и увеличение числа копий SMN2 заболевания1 (2\%) и 2 (4\%), соответственно. При анализе делеций экзонов 7-8 гена SMN1 показано, что у 15 (29\%), 2 (4\%) и 1 (2\%) больных CMA I, II и III типа ген SMN1 полностью делетирован.

Делеция экзонов 7-8 гена SMN1 и увеличение числа копий SMN2 статистически значимо различался в группах больных CMA I-II типа. Следует отметить, что увеличение копий гена SMN2 преобладало в группах больных со CMA II-III типа $5(10 \%)$ и $7(13,4 \%)$, соответственно, тогда как в группе больных со СМА Ізарегистрировано в 3 случаях, что составило $6 \%$.

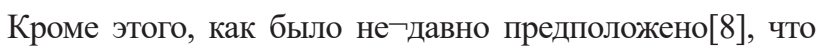
клинический полиморфизм спинальной мышечной атрофии может обуславливаться не только числом копий гена SMN1, но также свой вклад могут вносить и другие гены, лежащие в локусе $5 q 13$, проведен анализ числа копий генов NAIP в выборке больных СМА.

В результате исследованиявыявлено, что ген NAIP делетирован у 8 пациентов (19,2\%) со СМА I типа и у двоих пациентов (4\%) со CMA II типа. Также, у одного пациента со CMA II типа была обнаружена делеция экзона 8 гена SMN1 $1(2 \%)$. $\begin{array}{ll}\text { Таблица } 1 & \text { Результаты MLPA-анализа у пациентов } \\ \text { CMA }\end{array}$

\begin{tabular}{|l|l|l|l|l|}
\hline Типы СМА & I тип & II тип & III тип & Всего \\
\hline $\begin{array}{l}\text { Количество } \\
\text { выявленной } \\
\text { патологии(n) }\end{array}$ & 34 & 8 & 10 & 52 \\
\hline Del 7 exSMN1(\%) & $5(10 \%)$ & & & $5(10 \%)$ \\
\hline $\begin{array}{l}\text { Del 7 exSMN1 и } \\
\text { увеличение числа } \\
\text { копий SMN2 (\%) }\end{array}$ & $1(2 \%)$ & $2(4 \%)$ & $3(6 \%)$ \\
\hline Del 8 exSMN1(\%) & $15(29 \%)$ & $2(4 \%)$ & $1(2 \%)$ & $18(35 \%)$ \\
\hline Del 7 и 8 еxSMN1(\%) & $3(6 \%)$ & $5(10 \%)$ & $7(13,4 \%)$ & $8(15,3 \%)$ \\
\hline $\begin{array}{l}\text { Del 7 и 8 exSMN1 и } \\
\text { увеличение числа } \\
\text { копий SMN2 (\%) }\end{array}$ & $8(19,2 \%)$ & $2(4 \%)$ & & $10(19,2 \%)$ \\
\hline $\begin{array}{l}\text { Del 7 - 8 exSMN1 и } \\
\text { NAIP5 (\%) }\end{array}$ & & & & \\
\hline
\end{tabular}

\section{Обсуждение}

Известно, что большинство больных СМА (95\%) не имеют копий гена SMN1. Оставшиеся $5 \%$, представляют собой компаунд-гетерозиготы, несущие на одной хромосоме 5 делецию гена SMN1, а на другой — ген SMN1 с точковоймутацией или малыми делециями илиинсерциями [8].

Как указано выше, у больных СМА может наблюлдаться делеция только одного экзона - экзона 7 или экзона 8 гена $\mathrm{SMN1}$, что объясняется формированием химерного гена между генами SMN1 и SMN2. В различ встречаемости химерного гена у больных СМА варьирует от 3 до 12\%, что говорит о том, что данное явление нередко. Полагают, что в основе об $р$ разования химерного гена

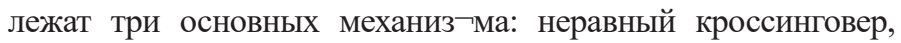


внутрихромосомнаяделе ᄀция и генная конверсия $[9,10]$. Эти же механизмы отвечают за мутации denovo в гене SMN. Известно, что только 98\% родителей больных СМА являются носителями гена данного заболевания, т.е. в большинстве случаев несут на одной из хромосом 5 одну поврежденную копию гена SMN1, а на другой — одну интактную копию гена SMN1 [11].

Пациенты с делецией экзона 7 и 8 гена SMN1 и NAIP5 представляли наиболее тяжелую группу больных CMA (мышечная слабость и контрактуры). Отсутствие гена NAIP служит индикатором протяженности делеций в локусе СМА и выявляется в большем проценте случаев с более тяжелой клиникой заболевания. Проведенное исследование подтвер ᄀдило полученные ранее данные о высокой степени мутиро $\neg$ вания NAIP $\neg$ гена при тяжелой форме CMA [12].

Ранее было показано, что увеличение копий гена SMN2, коррелирует не только с тяжестью проявления симптомов спинальной мышечной атрофии, но также с возрастом манифестации заболевания и продолжительностью жизни у больных СМА. В нашем исследовании, увеличение числа копий гена SMN2 преобладало среди пациентов со II и III типом СМА и в этих же группах отмечено позднее начало заболевания в возрасте 2-4,5 месяцев и более благоприятный прогноз, что согласуется с литературными данными.

Исходя из этого, можно предположить, что увеличение копий гена SMN2, приводит к повышению экспрессии полноценного белка SMN с центромерных копий гена на геном и тем мягче течение заболевания [13].

\section{Выводы}

Таким образом, метод MLPA позволяет не только подтвердить диагноз спинальной амиотрофии, но и уточнить тип спинальной амиотрофии в зависимости от выявленных изменений в генах SMN1, SMN2 и NAIP.

Клинический диагноз СМА главным образом, основан на идентификации гомозиготной делеции 7-го и 8-го экзонов гена SMN1.

Делеции гена NAIP и увеличение числа копии SMN2paсcматриваютдля оценки клинического фенотипа пациентов СМА.

\section{Литература}

1. Darras B.T. Spinal muscular atrophies. Pediatr. 2015; 62(3):743-766.

2. Faravelli I., Nizzardo M., Comi G.P., Corti S. Spinal muscular atrophy - recent therapeutic advances for an old challenge. Neurol. 2015; 11(6):351-359.

3. Monani U.R., Lorson C.L., Parsons D.W. et al. A single nucleotide difference that alters splicing patterns distinguishes the SMA gene SMN1 from the copy gene SMN2. Hum. Mol. Genet. 1999; 8(7):1177-1183.

4. Darras B.T. Non-5q spinal muscular atrophies: the alphanumeric soup thickens. Neurology. 2011; 77(4): $312-314$.

5. Maretina M.A., Kiselev A.B., Zheleznjakova G.Ju., Egorova A.A., Vaharlovskij V.G., Tishhenko L.I., Baranov B.C. Determination of the number of copies of the SMN2 gene in patients with spinal muscular atrophy of the North-West region of Russia. Medical Genetics. 2012; (4):25-28.

6. Watihayati. MS, Zabidi-Hussin AM, TangTH, Matsuo M, Nishio H, Zilfalil BA. Deletion analyses of SMN1 and NAIP genes in Malaysian spinal muscular atrophy patients. PediatrInt. 2007; 49(1):11-4.

7. Omrani O, Bonyadi M, Barzgar M. Molecular analyses of the SMN and NAIP genes in Iranian spinal muscular atrophy patients. Pediatr. 2009; 51(2):193-6.

8. Romanish M.T, Nakamura H., Lai C.B., et al. PloS ONE. 2009; 4(6):e5761.

9. Ogino S., Wilson R.B. Spinal muscular atrophy: molecular genetics and diagnostics. Expert Rev. Mol. Diagn. 2004; 4(1):15-29.

10. Maretina M., Kiselev A., Zheleznyakova G., Egorova A., Baranov V. Study of positive modifiers of spinal muscular atrophy severity in Russian patients. Nürnberg, Germany. 2012; 20: 334-335.

11. Ogino S., Gao S., Leonard D.G., Paessler M., Wilson R.B. Inverse correlation between SMN1 and SMN2 copy numbers: Evidence for gene conversion from SMN2 to SMN1. Eur. J. Hum. Genet. 2003; 11:275-277.

12. Zabnenkova V.V., Dadali E.L., Poljakov A.V. Analysis of the carriage of deletions in the SMN gene responsible for the occurrence of type I-IV spinal muscular atrophy. Medical Genetics. 2012. 11(1):3-9.

13. Scarciolla O., Stuppia L., De Angelis M.V., Murru S., Palka C., Giuliani R., et all. Spinal muscular atrophy genotyping by gene dosage using multiple ligation-de- pendent probe amplification. Neurogenetics. 2006; 7(4):239-76. 